\title{
Programa de Ideias Inovadoras do IFBA: proposição de melhorias baseada em critérios de avaliação
}

\author{
IFBA Innovative Ideas Program: proposition of improvements based on \\ evaluation criteria
}

\author{
Jamile Rosendo de Oliveira ${ }^{1}$ \\ Wagna Piler Carvalho dos Santos ${ }^{1}$ \\ Núbia Moura Ribeiro ${ }^{1}$ \\ Eduardo Manuel de Freitas Jorge ${ }^{2}$ \\ Marcio Luis Valenca Araujo ${ }^{1}$ \\ ${ }^{1}$ Instituto Federal da Bahia, Salvador, BA, Brasil \\ ${ }^{2}$ Universidade do Estado da Bahia, Salvador, BA, Brasil
}

\begin{abstract}
Resumo
Os concursos de inovação são iniciativas que geram estímulos para a criação de novas ideias. Algumas instituições apoiam essas iniciativas por meio de ações indutoras que premiam ideias inovadoras e, pelo lançamento de editais, essas instituições realizam processos de seleção. O objetivo deste artigo é avaliar a aderência do programa de ideias do IFBA com a sua política de inovação e realizar algumas comparações com programas de outras instituições. A metodologia aplicada foi a pesquisa de base exploratória bibliográfica, documental nos endereços eletrônicos de concursos em âmbito internacional e nacional e na mídia em geral. A partir da análise, foram demostrados os pontos fortes e fracos do programa e sugeridas melhorias. Conclui-se que o programa de ideias do IFBA está aderente à política de inovação do Instituto e aos concursos similares e de mesma qualidade, porém, salienta-se que esse concurso pode ampliar a sua visibilidade se aderir às sugestões propostas neste trabalho.
\end{abstract}

Palavras-chave: Inovação Tecnológica. Ideias Inovadoras. Empreendedorismo.

\begin{abstract}
Innovation contests are initiatives that generate incentives for the creation of new ideas. Some institutions support these initiatives through inducement actions that reward innovative ideas. Through the issuance of notices, these institutions carry out selection processes. The objective of this article was to evaluate the adherence of the IFBA's ideas program to its innovation policy and to make some comparisons with programs of other institutions. The applied methodology was exploratory bibliographical, documental research and in the electronic addresses of competitions at international and national level and in the media in general. From the analysis the strengths and weaknesses of the program were demonstrated and improvements were suggested. It is concluded that IFBA's ideas program is in line with the Institute's innovation policy and similar competitions of the same quality, but that it can increase its visibility by adding the suggestions proposed here.
\end{abstract}

Keywords: Technological innovation. Innovative ideas. Entrepreneurship

Área Tecnológica: Desenvolvimento Científico e Tecnológico. Prospecção Tecnológica. 


\section{Introdução}

A Inovação Tecnológica (IT) pode ser entendida como uma fonte geradora de mudanças da atualidade. Sendo assim, Reis (2011) define a Inovação Tecnológica como uma nova ideia, um evento técnico descontínuo, que, após certo período de tempo, é desenvolvido até o momento em que se torna prático e, então, usado com sucesso. Já o empreendedorismo foi conceituado por Baron e Shane (2007) como o reconhecimento de uma oportunidade na qual algo novo possa ser criado e que, a partir disso, possa dar abertura para o desenvolvimento de um novo mercado, uma nova matéria-prima ou um novo meio de produção.

Num mundo altamente globalizado, a cada mudança no ambiente internacional, intensifica-se a necessidade de integração da economia dos países, bem como o estímulo à competitividade para se manter atuante no mercado. A economia das nações precisa estar em sintonia para sobreviver e evoluir. E é nesse cenário que os empreendedores já atuantes, ou que ainda vão abrir um negócio, esperam criar novos empreendimentos realmente competitivos e com padrões de qualidade.

Diversos cenários, caracterizados por mudanças rápidas e substanciais, vêm impactando a sociedade nas últimas décadas, como exemplos apresentam-se: o processo de globalização; o aumento no ritmo de mudanças no ambiente econômico, institucional e tecnológico; e a substituição das tecnologias intensivas em capital e energia, e de produção inflexível e de massa pelas tecnologias intensivas em informação, flexíveis e computadorizadas. (ALMEIDA; TEIXEIRA, 2015, p. 2)

Como forma de acirrar esse cenário no Brasil, o Governo Federal lançou o programa Brasil Empreendedor. O escritor e empreendedor Dornelas (2008, p. 11) calcula que, para estimular o empreendedorismo, o programa capacitou mais de 6 milhões de jovens empreendedores no país, totalizando um investimento de mais de $\mathrm{R} \$ 8$ bilhões.

O Índice Global de Inovação (IGI), publicado anualmente pela Universidade de Cornell pelo Instituto Europeu de Administração de Empresas (INSEAD) e pela Organização Mundial da Propriedade Intelectual (OMPI), é considerado um ranking com propósito de colaborar com tomadores de decisões, em nível internacional, acerca da inovação como fonte de estímulo para o crescimento de uma economia.

Em uma análise econômica dos resultados brasileiros pelo IGI, frente à Lei n. 13.243/2016, conhecida como Novo Marco Legal da Ciência Tecnologia e Inovação (BRASIL, 2016), Miranda e Lima Verde (2019) explanam que a situação da economia brasileira, quando comparada com a dos países desenvolvidos, está muito aquém. Eles ainda relatam que a situação do país, quando confrontada com os países emergentes, como Coreia, Índia e China no quesito inovação, também não é adequada, uma vez que as despesas em inovação na indústria brasileira são voltadas, principalmente, para aquisição de equipamentos e não para Pesquisa e Desenvolvimento (P\&D), além de que é pequeno o percentual das empresas que inovam no Brasile desenvolvem parcerias com Universidades.

Relatado na nota técnica do IPEA (2018), a China ocupa a sétima posição para crédito doméstico ao setor privado, a segunda para comércio, competição e escala de mercado. A África do Sul ocupa a primeira posição para capitalização de mercado. A Índia ficou com a quarta posição no indicador facilidade na proteção de investidores minoritários: 
O Brasil ocupa a $64^{\mathrm{a}}$ posição do IGI 2018, subindo cinco posições desde 2017. Há vários anos, a Índia tem um desempenho de destaque, haja vista seu nível de renda per capita. O IGI 2018 identificou vinte países que têm desempenho acima do esperado para seu nível de desenvolvimento, e a África do Sul (48a posição) entrou no grupo pela primeira vez. (IPEA, 2018, p. 7)

Já em 2019, o IGI aponta a Suíça como o país mais inovador do mundo, seguida da Suécia, Estados Unidos da América (EUA), Países Baixos e Reino Unido. E o Brasil, que vinha tentando ganhar visibilidade no ranking, perdeu duas posições e passou a ocupar a $66^{\circ}$ colocação:

O Brasil, maior economia da região, ocupa a $66^{\mathrm{a}}$ posição global este ano. As áreas com melhor desempenho compreendem variáveis importantes, como gastos com P\&D e empresas globais que investem intensivamente em $\mathrm{P} \& \mathrm{D}$, além da qualidade das publicações científicas e universidades. (WIPO, 2019, p. 4)

Diante desse cenário, o Brasil, nos últimos anos, vem investindo nas áreas de ciências, tecnologia e inovação a fim de buscar equilíbrio e paridade nesse panorama internacional. O Ministério da Ciência, Tecnologia, Inovação e Comunicação (MCTIC) lançou a Estratégia Nacional para a Implementação de Políticas de Ciência, Tecnologia e Inovação (ENCTI) para ser aplicada durante o período de 2016 a 2022.

O objetivo delineado na ENCTI é abordar os desafios e traçar estratégias no emparelhamento do Brasil com países mais desenvolvidos no campo da Ciência, Tecnologia e Inovação (CT\&I), promover a inovação como destaque para o aumento da competitividade e abertura de mercados, de modo que o Brasil possa vir a se destacar em diversos setores.

Além da ENCTI, o Governo Federal lança mão do Programa Brasil Maior que traz medidas que estimulam a competitividade e o investimento em inovação, a exemplo da desoneração tributária, e do apoio e financiamentos que conferem maior disponibilidade de créditos para atividades relacionadas com a inovação.

Trazendo o enfoque para o Estado da Bahia, percebe-se que esse Estado tem crescido no cenário de empreendedorismo e inovação, mas ainda não apresenta uma relevância no cenário nacional. Por meio da Secretaria de Ciência, Tecnologia e Inovação do Estado da Bahia (SECTI, 2020) e em parceria com a Fundação de Amparo à Pesquisa do Estado da Bahia (FAPESB, 2020), iniciativas para consolidação de CT\&I são propostas por meio de novos programas de pesquisa e inovação como meio de empreender o estado e contribuir com o desenvolvimento da região, a exemplo da concessão de bolsas para novos pesquisadores.

Segundo dados da Pesquisa de Inovação (PINTEC), em 2014, o Estado teve uma pequena parcela de participação na introdução de inovação no mercado comparado com o resto do país, visto que a pesquisa revelou que o Estado contribuiu com um percentual de participação de apenas $1,7 \%$ do montante total das indústrias que foram pesquisadas.

$\mathrm{Na}$ Pintec de 2017, houve uma queda nos índices de inovação do país, e o estado mostrou que vem implementando ações em contraposição a esses índices quando se refere à taxa de inovação nas indústrias. Houve um crescimento no triênio 2015-2017 com um saldo positivo de implementação de inovação de máquinas e equipamentos.

Ainda no Estado da Bahia, o Parque Tecnológico é tido como um grande centro de desenvolvimento e pesquisa tecnológica e é nele que algumas ideias são incubadas por meio de 
projetos. Utilizando o conceito da Hélice Tríplice, trazido por Etzkowitz e Zhou (2017), como um processo em desenvolvimento contínuo e tendo como meta criar um ecossistema para inovação empreendedorismo, o Parque promove e favorece a articulação entre universidades/institutos de educação, governo e o setor privado em face da inovação e do conhecimento.

Ainda há muito que se fazer para o aumento da competitividade das empresas da Bahia. Posto isso, Instituições de fomento e Universidades e Instituições de Ensino Superior públicas têm participado ativamente com o objetivo de fomentar o desenvolvimento de pesquisas e a inovação com o propósito de incentivar o empreendedorismo no Estado.

As Universidades e Instituições de Ensino Superior públicas têm incumbências empreendedoras e responsabilidades no desenvolver das regiões às quais são pertencentes. No trato com atividades de transferência de tecnologias, incentivos à propriedade intelectual, incubação de empresas e as docentes em atividade constantes relacionadas às pesquisas traçam esse novo perfil de unidades com função empreendedoras que contribuem com desenvolvimento econômico-social da região na qual estão inseridas.

Além dessas atividades citadas, também existe a incumbência de essas instituições promoverem ações indutoras de ideias inovadoras com objetivo de tentar levá-las para o mercado.

No cenário internacional, ganharam destaque alguns concursos, como o promovido pela Universidade de Harvard, nos Estados Unidos, por meio do Village to Raise a Child, o prêmio Creator Awards, promovido pela Wework, e o Invent for the planet, promovido pela Universidade do Texas, EUA.

No Brasil, tem-se, a título de exemplo, a Universidade São Paulo (USP, 2016) que lançou em 2016 um programa específico e voltado para os alunos dos cursos de Engenharia de Computação, Engenharia Elétrica e de Ciência da Computação, a Escola Nacional de Administração Pública (ENAP), que lança editais para prospectar melhorias na gestão das instituições públicas, e a Agência Nacional de Petróleo (ANP), que busca soluções inovadoras para o setor de petróleo, gás e biocombustíveis.

Na Bahia, por meio de programas e de ações inovativas, a Fapesb e o Serviço Brasileiro de Apoio às Micros e Pequenas Empresas (SEBRAE) disponibilizam concursos/editais de inovação. A Universidade Federal da Bahia (UFBA) lançou o PaIdeia, e o Instituto Federal de Ciência e Tecnologia da Bahia (IFBA) realizou o concurso Uma ideia na cabeça, uma inovação na mão.

O IFBA (2019), objeto do trabalho em questão, promove a cultura da inovação e empreendedorismo tecnológico no âmbito do Instituto, por meio do concurso Uma ideia na cabeça, uma inovação na mão (2019), que premia jovens estudantes e servidores com ideias inovadoras e com potencial para criar ou melhorar produtos, processos ou serviços para sociedade.

Entende-se que tais concursos lançados por essas instituições são ações indutoras que objetivam prospectar novos conhecimentos e aperfeiçoamentos. E, a partir da comercialização dessas ideias, espera-se a alavancagem do mercado com o desenvolvimento de novos produtos, aumentando a competitividade das empresas e criando valor e lucro para elas ou a resolução de problemas sociais.

Este trabalho por meio do histórico de realização do concurso de ideias inovadoras pelo IFBA, sob responsabilidade da Pró-Reitoria de Pesquisa, Pós-Graduação e Inovação (a cargo do Departamento de Inovação), avaliará se existe uma aderência desse tipo de ação indutora à Política de Inovação da Instituição, além de verificar se os critérios utilizados pelo programa 
de ideias está adequado aos encontrados em outros programas similares do mesmo nível de qualidade.

O objetivo desta pesquisa é propor sugestões de melhorias no programa de ideias do IFBA, além de relatar, se existir, pontos de conflito entre o programa e a Política de Inovação do Instituto.

\subsection{Inovação e Empreendedorismo}

Inovação e empreendedorismo são destaques quando se fala de criação de novos empregos, de crescimento econômico, de competitividade mercadológica, de ciência e tecnologia. Então, Davidsson (2005) considera que o empreendedorismo não é apenas a criação de novos negócios, mas também o aparecimento de novos mercados.

A inovação pode ser compreendida como a introdução de algo novo e propenso a abrir novos mercados. Assim, Scott (2016) definiu a inovação como algo diferenciado que agregue valor. Para o autor, é preciso que esse novo produto se associe com outros ingredientes importantes, já que, para ser mais que uma ideia, é necessário que gere lucros, melhore o desempenho de um processo, forneça um benefício social ou resolva um problema pessoal para ser qualificado como inovação. O economista Joseph Schumpeter (2017) também traz o conceito de que as empresas inovam a fim de obterem lucro. É, a partir desses conceitos, que se interligam a inovação com o empreendedorismo.

O empreendedorismo seria o elo para se chegar ao mercado competitivo. "O empreendedorismo pode ser compreendido como a arte de fazer acontecer com criatividade e motivação" (BAGGIO; BAGGIO, 2014, p. 26). As empresas que não tiverem predisposição à mudança e se adequarem a uma nova realidade, em meio a um mercado mutável e competitivo, tendem ao fracasso.

\subsection{Concursos de Inovação que Premiam}

Entende-se que a gestão de ideias pode ser um processo pelo qual as empresas, com desígnio de expandirem e de competirem, buscam conhecer a demanda de produtos/serviços da sociedade global ou de um local específico que afetem o desenvolvimento econômico destes, $e$, a partir da carência de algo, surgem a ideia e a posterior criação do novo.

\section{Metodologia}

O presente artigo pretende, conforme exposto na introdução, levantar o histórico de ações indutoras de inovação, sob formato de concursos que buscam prospectar ideias inovadoras, a fim de trazer uma análise comparativa com o concurso de ideias inovadoras do IFBA.

O foco do trabalho foi o concurso Uma ideia na cabeça, uma inovação na mão, do IFBA, de modo que foi comparado o seu critério de avaliação com o dos outros concursos historicizados no artigo, promovidos com a mesma finalidade, e em seguida foi avaliado se existe aderência da ação do Instituto com a sua própria Política de Inovação. Ao final, depois de feita a comparação dos critérios de avaliação dos respectivos concursos, incluiu-se sugestões acerca da possibilidade de melhoramento no concurso do IFBA. 
A coleta dos dados foi realizada por meio de pesquisa documental nos endereços eletrônicos das instituições e na mídia em geral e por comunicação via e-mail no período de janeiro de 2018 a maio de 2020. Então, trata-se de uma pesquisa exploratória. A pesquisa documental também foi objeto da análise por meio dos editais das organizações promotoras dos concursos de inovação e a pesquisa bibliográfica baseou-se na contribuição de diversos autores relacionados aos assuntos acerca da inovação e empreendedorismo tendo o Brasil e a Bahia como foco.

As etapas da pesquisa foram construídas a partir de referencial teórico, levantamento de dados nos sites das instituições, historicizados os dados de alguns concursos de inovação em nível internacional que tiveram o Brasil como sede ou participantes brasileiros finalistas, concursos de alguns órgãos do país como ENAP e ANP e, por fim, do Sebrae e Fapesb como agências de fomento responsáveis por promover a inovação e o empreendedorismo no Estado da Bahia, e dos concursos PaIdeia, da UFBA, e Uma ideia na cabeça, uma inovação na mão, do IFBA.

A abordagem da pesquisa é metodológica, de natureza aplicada. Do ponto de vista de seus objetivos, a pesquisa é de natureza exploratória, com estudo de caso do concurso do IFBA, com procedimentos técnicos documentais e bibliográficos e uma análise comparativa com os demais concursos expostos ao longo do trabalho.

O estudo de caso é entendido pela definição traçada por Yin (2001) como um estudo completo de maneira que permita um amplo e detalhado conhecimento. Assim definido por Gil (2008), o método comparativo origina-se da investigação de indivíduos, classes, fenômenos ou fatos, com perspectivas de ressaltar as diferenças e as similaridades entre eles.

Na Figura 1 é mostrado o roteiro metodológico da presente pesquisa:

Figura 1 - Roteiro metodológico

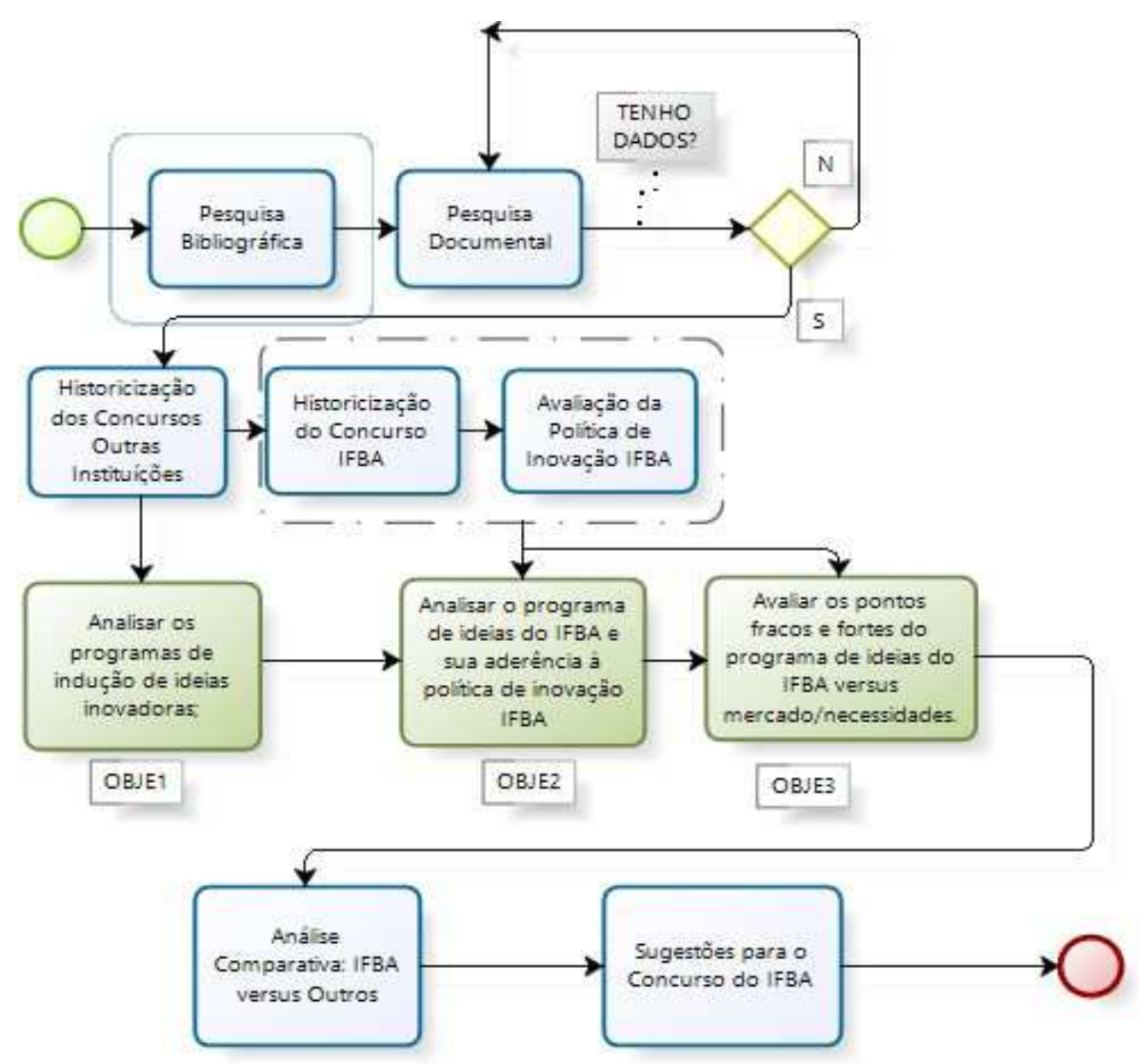

Fonte: Elaborada pelos autores deste artigo (2019) 
Iniciou-se com a pesquisa bibliográfica e, em seguida, foi realizada uma pesquisa exploratória documental, utilizando sites das instituições promotoras das ações indutoras de inovação, nas quais foram historicizados os concursos. Os objetivos e os critérios de avaliação foram obtidos por meio dos editais. Foi feita uma análise da política de inovação do IFBA. Logo em seguida, a partir dos históricos, foram analisados os programas de ideias indutoras, conforme delineado no primeiro objetivo específico; em seguida, foi analisado o concurso Uma ideia na cabeça, uma inovação na mão, do IFBA, e a sua aderência à política do órgão, de acordo com o segundo objetivo específico e, concluindo o terceiro objetivo específico, foram avaliados os pontos fracos e fortes do programa de ideias do IFBA.

Efetivado os objetivos específicos, o próximo passo foi a análise comparativa do IFBA com as outras ações indutoras explanadas no artigo e concluído o objetivo final que é trazer sugestões para melhorias no concurso do IFBA.

\section{Resultados e Discussão}

As propostas foram julgadas segundo os enquadramentos constantes nos editais, conforme os critérios de avaliação que, na maioria dos concursos apresentados, enfatizavam que a proposta precisava ser original, ter aplicação prática, mercado potencial e diferencial em relação às existentes.

Quanto à temática, a maioria dos editais citados utilizou temas gerais que direcionavam situações novas para a sociedade em todas as áreas. As áreas de saúde, química, sociais e informática tiveram destaque quanto à propositura dos temas, com notoriedade para a criação de aplicativos que possibilitem facilidades para a vida das pessoas.

Os concursos da ANP e da ENAP utilizaram temas específicos para a seleção das propostas, já que o primeiro é voltado para indústria petrolífera e o segundo tem como foco a capacitação de servidores públicos, sendo os temas direcionados quanto às atividades-fins desses órgãos.

Em uma análise acerca das ações indutoras de inovação historicizadas no presente artigo, a Fapesb foi a instituição com maior gasto orçamentário nesses tipos de programas. Na edição de 2015 , a dotação orçamentária gasta com os finalistas premiados foi de $\mathrm{R} \$ 510.000,00$. Já o Sebrae (2017), fomentando os pequenos e médios negócios, investiu $R \$ 20.000 .000$ em dois anos para que os projetos fossem desenvolvidos. Então, entende-se que esses são órgãos com objetivo definido, voltados para ações de fomento e de empreendimento, que recebem do governo verba para tais finalidades.

Já a Instituição de ensino IFBA, que nos primeiros editais lançou premiação com objetos eletrônicos ou materiais para uso acadêmico, alavancou a premiação do seu concurso nas edições seguintes. A edição recente, lançada no início de 2019 , ofereceu mais de $\mathrm{R} \$ 28.000,00$, conforme descrito no portal do Instituto, como prêmio a ser distribuído entre os finalistas.

O concurso PaIdeia (2015), da UFBA, que também teve como alvo os docentes, alunos e funcionários do quadro da Universidade, contou com uma única edição, a de 2015. Foram distribuídos $\mathrm{R} \$ 48.000,00$ em prêmios de bolsas de iniciação tecnológica, por um período de um ano, para que os projetos fossem desenvolvidos como uma espécie de pré-incubação. 
Em relação aos concursos internacionais, a análise citou quatro deles que tiveram o Brasil como sede em alguma edição ou tiveram alunos de Universidades/Instituições brasileiras se destacando quanto às inovações constituintes.

O Village to Raise a Child (2018) é voltado para todos os estudantes, a partir do nível médio, e tem como atrativo inovador o fato de buscar soluções para problemas na comunidade na qual o participante está inserido. O ponto significativo desse programa é que a premiação é voltada para o desenvolvimento da ideia vencedora.

O WeWork Creator Awards (2019) foi realizado em diversas Universidades do Mundo, teve a criação inovadora por categorias empresarial, ONGs e artísticas. O Invent for the planet (2019) também teve como objetivo a resolução de problemas relacionados a questões acerca da insegurança quanto à utilização da água, à disseminação de doenças e à criação de novas tecnologias para a sala de aula como objetivo da ação.

O Seeds for the Future (2016), promovido pela empresa Huawei, voltou-se para uma temática bem atual como a Internet das Coisas. O concurso foi direcionado aos alunos da USP (2016) e também teve uma premiação voltada para capacitação e treinamento acerca de tecnologias $e$ conhecimento de práticas da cultura de outro país, no caso a China, país considerado referência sobre o tema de inovação.

Ações, como as registradas na pesquisa, que adotam uma postura de fomentar e prospectar ideias novas precisam se manter ativas, mesmo que muitas dessas ideias talvez não cheguem a ser desenvolvidas devido à escassez de participação das empresas privadas que contribuem para fomentar esse contexto inovador.

Mesmo diante do atual crescimento, os dados ainda mostram a Bahia abaixo da zona confortável no que diz respeito à inovação, conforme revelado no referencial teórico do artigo. Então, é preciso que essas ações se mantenham contínuas para que possam contribuir com a busca de novas ideias que venham a induzir inovação, competitividade e empreendedorismo no estado baiano. A entrada da inovação aliada ao empreendedorismo no mercado da região analisada, que se configura como a entrada de novos produtos e novos modelos de negócios, é iminente para que haja um crescimento da indústria local.

\subsection{Da Lei de Inovação e do Novo Marco Legal}

Conforme prevê o artigo $1^{\circ}$, Capítulo I, das disposições preliminares da Lei n. 10.973, de 2 de dezembro de 2004, revisada pela Lei n. 13.243/2016, a Lei de Inovação tem como objetivo estabelecer medidas que incentivem e fomentem a inovação e a pesquisa tecnológica científica visando à capacitação e ao alcance da autonomia tecnológica das indústrias para que haja desenvolvimento do sistema produtivo nacional e regional do país (BRASIL, 2004).

A Lei de Inovação prevê o fomento à inovação por cada ente federado e o estabelecimento de alianças para desenvolvimento de projetos/produtos/processos para a transferência de tecnologias inovadoras, a criação de Incubadoras e parques tecnológicos e para o estímulo da relação entre as universidades e as empresas privadas.

A concessão de recursos humanos e a subvenção econômica, em que os benefícios com apoio financeiro não precisam ser devolvidos, bônus financeiro, financiamentos, fundos de 
participação e uso de poder de compra do Estado, entre outros, são benefícios que as empresas vêm recebendo por meio do Estado como forma de incentivar a inovação.

O Novo Marco chega para facilitar os processos de importação, facultou aos professores com regime de dedicação exclusiva a participação no processo de inovação nas empresas e que recebam por isso, vinculou os prazos dos instrumentos jurídicos decorrentes da atividade de CTI à duração do projeto e decidiu que todo aporte de capital em ações relacionadas a esse tipo de atividade são considerados investimento, podendo ser abatido do imposto de renda pelas empresas, desse modo, as prestações de contas tornaram-se flexibilizadas, quando simplificou as questões relacionadas à burocracia.

\subsection{IFBA: a Política de Inovação e o Concurso Uma ideia na cabeça, uma inovação na mão}

O IFBA, vinculado ao Ministério da Educação (MEC), tem como prioridade a educação tecnológica profissional pública em vários níveis de escolaridade, incluindo programas de Pós-Graduação e o Mestrado em Propriedade Intelectual (PROFNIT).

A cargo da Pró-Reitoria de Pesquisa, Pós-Graduação e Inovação (PRPGI), por intermédio do Departamento de Inovação (DINOV), estão as atividades de promoção das ações de proteção da propriedade intelectual e de estímulo à transferência tecnológica, bem como o contato constante com instituições e empresas na área de fomento à pesquisa, ciência e inovação tecnológica.

O concurso Uma ideia na cabeça, uma inovação na mão (2019) está amparado pela Política de Inovação do IFBA, que foi atualizada conforme o novo Marco Legal, Lei n. 13.243/2016, a partir da deliberação do documento a respeito da atribuição perene do Instituto em estimular e valorizar a atividade criativa, produção científica, tecnológica e artística do seu corpo discente, docentes, técnicos-administrativos, estagiários, pesquisadores, prestadores de serviços, órgãos ou empresas contratadas ou contratantes.

A política estabelece que os conhecimentos obtidos por meio das proteções produzidas no Instituto deverão ser repassados à sociedade. O concurso do IFBA também objetiva que a partir das ideias criadas e repartidas para a sociedade, no contexto do concurso, depois que tenham se transformado em um projeto, possam vir a se tornar objetos de posse temporária, a qual terá a Instituição como detentora dos direitos da propriedade intelectual.

Outro tópico contextualizado na Política de Inovação referiu-se ao compartilhamento da infraestrutura do IFBA, a saber, seus laboratórios, equipamentos, instrumentos, materiais e demais instalações como forma de incentivo, visto que há a possibilidade de os alunos terem acesso às instalações físicas do instituto para desenvolverem a criação de suas ideias.

Acerca do inventor independente, o IFBA decidirá sobre adoção de sua criação, visando à elaboração de projeto voltado a sua avaliação para futuro desenvolvimento, incubação, utilização e industrialização pelo setor produtivo

A política cita as atribuições do Dinov e entre elas estão o estímulo à proteção das criações e à inovação e a possibilidade de opinar pela conveniência e de promover a proteção das criações desenvolvidas na instituição, sendo esta uma possibilidade que possa vir a surgir, como já apontado, a partir do concurso Uma ideia na cabeça, uma inovação na mão, e que venha ser objeto de proteção pelo órgão depois de ouvido o Comitê de inovação. 
O concurso do IFBA tem uma média expressividade, já que está voltado apenas para o público interno do órgão, mas, ao longo dos anos, obteve uma majoração no número de participantes com interesse em divulgar a sua ideia no programa.

A ação divide-se em categorias quanto ao grau de escolaridade, o que não difere das outras instituições que também separam as premiações por categoria, por grau de instrução, o que, por sua vez, facilita a concorrência por parte dos candidatos, nivelando os concorrentes e então premiá-los.

Verificou-se que houve uma evolução no regulamento do concurso (edital), ao passo que os editais anteriores vinham mantendo uma mesma linha de avaliação e tiveram os critérios diversificados nas últimas edições mudando, assim, o formato da avaliação dos projetos submetidos.

A pontuação foi acrescida no quesito Ineditismo, que define a apresentação de solução que não tenha sido publicada ou que seja considerada inovadora, e o critério Aplicação, quanto ao potencial da ideia para aplicação comercial ou industrial, viabilidade técnica, viabilidade de implementação (dispêndios com gastos de implementação) e o impacto social da proposta. Critérios importantíssimos que denotam o caráter inovador da criação.

Quando se trata do continuísmo, o IFBA, como instituto de ensino tecnológico, dá seguimento a esse tipo de ação como forma de fomento à sua função empreendedora na Bahia. E ainda introduz novos projetos voltados ao empreendedorismo e à inovação, como o Hotel de Projetos, em parceria com o Sebrae, amparando projetos com características inovadoras e qualificando-os para o mercado empreendedor como uma espécie de pré-incubação, cujos projetos vencedores são capacitados para desenvolvimento da sua proposta e posterior introdução no mercado.

\subsection{Análise Comparativa dos Critérios de Julgamento das Instituições Executoras de Ações Indutoras de Inovação}

Os critérios de avaliação das propostas submetidas nessas ações de indução de ideias foram deliberados em edital. A Fapesb, utilizando de critérios previamente definidos para avaliar as propostas recebidas do concurso Ideias Inovadoras, utilizou-se dos seguintes critérios indicados: originalidade; considerado novo, original, criativo, perfil empreendedor; aceitação dessa ideia no mercado, clareza quanto à descrição da ideia, os impactos para a economia, sociedade e para o ambiente.

Já o Sebrae com o concurso Sebrae de Inovação, voltado para as micros e pequenas empresas, avaliou as propostas sob os critérios consistência e viabilidade, sua aplicação prática, escalabilidade (que confere o aumento de um faturamento sem necessitar de aumentar os custos), o potencial mercadológico da proposta e geração de valor e a medição do grau $e$ impacto da inovação.

A UFBA utilizou os seguintes critérios de avaliação: clareza na descrição do problema, viabilidade técnica, análise do risco e retorno daquilo que foi planejado, quanto a sua exequibilidade, a qualidade e complementaridade da equipe e a aplicabilidade/funcionalidade da ideia, caso seja posta em prática.

No concurso Inovação no setor público da ENAP, os critérios foram baseados na eficiência quanto à prestação dos serviços, pleiteando por meio de serviços inovadores uma forma de utilização eficiente dos recursos, resultados eficazes na realização da prestação do serviço público e mecanismos de transparência e controle da sociedade desses serviços. 
O prêmio ANP de Inovação propõe, na sua avaliação, a originalidade da proposta, que pode ser definida como novidade, ineditismo; e relevância, que se aplica ao critério da importância daquele objeto/serviço para a sociedade e a aplicabilidade e funcionalidade quando posta em prática.

O concurso Uma ideia na cabeça, uma inovação na mão, do IFBA, trouxe os critérios da aplicabilidade e colocou nesse mesmo critério a avaliação da possibilidade de sua aplicação para o mercado, comércio ou indústria; a viabilidade técnica, econômica; e o impacto social. Quanto à clareza, o edital propõe uma descrição clara e objetiva do problema, a eficácia quanto ao grau de produzir resultados e o ineditismo ou a novidade propostos pelo projeto.

O edital 2019 traz outro formato de avaliação que se dá por meio dos vídeos recebidos com a apresentação das propostas, os Pitches, também serão avaliados a apresentação, a clareza, o conteúdo e o impacto (IFBA, 2019).

A Tabela 1 apresenta um comparativo dos critérios de cada instituição agente das ações indutoras de inovação relatadas no presente artigo:

Tabela 1 - Comparação dos critérios de avaliação de concursos de ideias inovadoras

\begin{tabular}{|c|c|c|c|c|c|c|}
\hline \multicolumn{7}{|c|}{ Comparação dos Critérios de Avaliação Propostos } \\
\hline PROGRAMA & $\begin{array}{c}\text { UMA IDEIA NA } \\
\text { CABEÇA, UMA } \\
\text { INOVAÇÃO NA MÃO } \\
\text { (IFBA) }\end{array}$ & $\begin{array}{l}\text { PAIDEIA } \\
\text { (UFBA) }\end{array}$ & $\begin{array}{c}\text { IDEIAS } \\
\text { INOVADORAS } \\
\text { (FAPESB) }\end{array}$ & $\begin{array}{l}\text { SEBRAE DE } \\
\text { INOVAÇÃo } \\
\text { (SEBRAE) }\end{array}$ & $\begin{array}{l}\text { Inovação No } \\
\text { SETor Público } \\
\text { (ENAP) }\end{array}$ & $\begin{array}{c}\text { PrêMIO ANP } \\
\text { DE INOVAÇÃo } \\
\text { TeCNOLógica } \\
\text { (ANP) }\end{array}$ \\
\hline INOVAÇÃO & $\mathrm{x}$ & & $\mathrm{x}$ & $x$ & $x$ & \\
\hline $\begin{array}{l}\text { ORIGINALIDADE/ } \\
\text { INEDITISMO }\end{array}$ & $x$ & & $\mathrm{x}$ & & & $x$ \\
\hline $\begin{array}{c}\text { IMPACTO } \\
\text { MERCADOLÓGICO }\end{array}$ & $x$ & & $x$ & $x$ & & \\
\hline VIABILIDADE & $\mathrm{x}$ & $\mathrm{x}$ & & $\mathrm{x}$ & & \\
\hline DIFERENCIAÇÃO & & & $\mathrm{x}$ & & & \\
\hline APLICABILIDADE & $\mathrm{x}$ & $\mathrm{x}$ & $\mathrm{x}$ & & $\mathrm{x}$ & $\mathrm{x}$ \\
\hline RELEVÂNCIA & & & & & & $\mathrm{x}$ \\
\hline EFICÁCIA & $\mathrm{x}$ & & $\mathrm{x}$ & & & \\
\hline $\begin{array}{c}\text { PERFIL } \\
\text { EMPREENDEDOR }\end{array}$ & & & $x$ & $\mathrm{x}$ & & \\
\hline $\begin{array}{c}\text { APRESENTAÇÃO } \\
\text { DA PROPOSTA }\end{array}$ & $\mathrm{x}$ & $\mathrm{x}$ & $\mathrm{x}$ & & & \\
\hline ESCALABILIDADE & & & & $\mathrm{x}$ & & \\
\hline $\begin{array}{l}\text { UTILIZAÇÃO } \\
\text { EFICIENTE }\end{array}$ & & & $x$ & & $x$ & \\
\hline $\begin{array}{l}\text { FOCO NAS } \\
\text { PESSOAS }\end{array}$ & & & & & $x$ & \\
\hline $\begin{array}{l}\text { IMPACTO SOCIAL, } \\
\text { ECONÔMICO E } \\
\text { MEIO AMBIENTE }\end{array}$ & & & $x$ & & & \\
\hline $\begin{array}{l}\text { TRANSPARÊNCIA } \\
\text { E FOCO SOCIAL }\end{array}$ & & & & & $x$ & \\
\hline
\end{tabular}

Fonte: Elaborada pelos autores deste artigo com base em dados dos editais da Fapesb, do Sebrae, da UFBA, do IFBA, da ANP e do ENAP (2019) 
Os critérios consistem em medir a performance de cada proposta de forma que sejam vislumbradas, em cada ideia, as qualidades inerentes à asserção dos concursos que têm como finalidade o fomento de ideias para que sejam, posteriormente, desenvolvidas e implementadas de forma que a obtenção de produtos novos $e$ inovadores tragam impacto mercadológico $e$ abram a competitividade regional.

\subsection{Proposição de Melhorias Baseada em Critérios de Julgamento}

O Programa apresentou progressos a cada novo edital da ação indutora de inovação em relação aos anteriores. Pontos fortes, em sua maioria, e alguns pontos fracos que serão relatados como forma de contribuir como melhoramento da ação.

Os pontos fortes destacados foram:

a) A inclusão dos docentes e técnicos administrativos, visto que isso agrega maior potencial na temática das propostas.

b) O preenchimento dos formulários de submissão foi restrito à opção on-line por meio de um link no site do Dinov.

c) A Inclusão (na última edição) de diversos formatos quanto à apresentação da proposta, visto que nas edições anteriores esse quesito não ficava claro.

d) A inclusão de uma segunda etapa para seleção das novas ideias, em que se determina o recebimento dos Pitches.

e) A premiação dos Pitches mais populares, isso foi uma inovação que o concurso trouxe que se torna um diferencial em relação aos editais anteriores.

f) Os progressos na procura para a submissão de propostas, com um relativo aumento de inscrições recebidas.

A seguir, estão apresentados alguns pontos fracos levantados durante a pesquisa:

a) A falta de explicações mais consistentes como forma de sanar dúvidas acerca do concurso no site do Departamento de Inovação.

b) O baixo número de inscritos, considerado baixo mesmo havendo um aumento na procura para submissão de propostas.

c) A disponibilização de mais informações sobre as outras edições no Portal do departamento.

d) A percepção de que, quando vislumbrado que a proposta do concurso é o fomento ao empreendedorismo, o edital não trouxe o item perfil empreendedor da proposta no critério de avaliação com destaque para uma pontuação máxima.

e) Um ponto bastante discutido na atualidade e que poderia ser considerado critério de avaliação, seria o de desenvolvimento sustentável da proposta, ou seja, um critério que levasse em conta se a proposta de produto/serviço apresentasse crescimento econômico aliado à preservação do meio ambiente.

Quanto à propositura de melhorias, uma questão que poderia ser sugerida no concurso Uma ideia na cabeça, uma inovação na mão seria a possibilidade de introdução de uma categoria 
voltada para prospectar ideias de pessoas externas à instituição, a exemplo de uma categoria voltada para os inventores independentes, já que o regulamento interno do IFBA impulsiona a relação dos Núcleos de Inovação Tecnológica (NIT) com os inventores independentes.

A gestão do programa poderia criar um website voltado especificamente para o programa, de forma que os participantes pudessem acompanhar todas os passos da ação inovadora, que poderia ser atualizada semanalmente, assim, seria possível visualizar também a relação dos premiados de todas as edições com as supostas ideias/temas e as áreas de maior envio de propostas.

Nesse cenário, o portal do concurso poderia disponibilizar material para a conscientização dos alunos quanto à importância da inovação para o contexto atual da economia do país ou da região baiana e material informativo acerca do tema empreendedorismo. Também poderia ser criado um banco de ideias catalogadas, pois isso seria uma boa sugestão para que as pessoas pudessem contribuir com ideias inovadoras, assim, formaria-se uma vitrine para que as empresas pudessem acessar e coletar informações.

Fazer parcerias de forma que o concurso fosse subsidiado, no todo ou em partes, por órgãos de fomento, principalmente quanto às premiações, como forma de atrair mais inscrições, seria outra sugestão.

Quanto às propostas, poderia ser feito um tipo de consulta à comunidade do IFBA, antes do lançamento do concurso, com a finalidade de se obter sugestões acerca de mudanças no programa e/ou inclusão de algum tema específico, ou até alguma sugestão de inclusão de premiação, de forma que viessem a se adequar ao público-alvo e ao intento do concurso, por exemplo, a possibilidade de viagens para locais, cidades, países que sejam locus de referência em inovação.

Quanto aos temas, sugere-se o lanlamento de alguma edição do concurso voltado para temas específicos que possam solucionar problemas atuais da região, no caso na Bahia. As temáticas poderiam ser direcionadas para questões relevantes atuais, como a problemática da mobilidade urbana e possíveis soluções para o caos que atinge os transeuntes; questões que possam trazer soluções relacionadas ao aumento da criminalidade contra as mulheres, feminicídio; e questões voltadas para doenças sazonais, entre diversos temas que poderiam ser pré-testados.

Ainda relacionado a temas específicos, uma sugestão seria algo para a categoria dos técnicos-administrativos e/ou para os docentes, voltado para o recebimento de propostas que promovessem melhorias internas nos processos administrativos do instituto, de forma que agregasse inovação na forma de atendimento ou nos programas, propondo melhoria e agilidade.

Ao final de cada edição, poderia haver uma pesquisa para medir o nível de satisfação com relação ao concurso por parte do público que submeteu suas propostas, de forma que pudesse ser acolhida a percepção das pessoas em relação ao concurso.

\section{Considerações Finais}

A pesquisa aqui registrada utilizou como locus de análise o concurso Uma ideia na cabeça uma inovação na mão, do IFBA (2019), com o objetivo de validar se a proposta do concurso está aderente à política de inovação do Instituto e se os critérios de avaliação utilizados para selecionar as propostas vencedoras, com desígnio em inovação, estão em consonância com outros programas de mesma finalidade que premiam. 
A partir da criação deste documento foi produzida matéria explícita sobre o funcionamento de alguns concursos de inovação, incluído alguns programas internacionais e nacionais, sendo estes regulamentados por meio de editais, chamadas públicas ou manuais do candidato quanto à trajetória das iniciativas até se chegar a uma ideia premiada que tenha características inovadoras.

No histórico das ações indutoras, foram demonstrados os temas criativos relacionados com a inovação, os finalistas dos concursos em análise e as premiações recebidas para as melhores ideias finalistas e vencedoras dos programas.

O objetivo da construção deste artigo foi historicizar ações de inovação, com foco no programa de ideias inovadoras do IFBA, já que o Instituto é direcionado para um ensino de base tecnológica, e o programa proposto tem o intento de fomentar a inovação e o empreendedorismo no estado

Foi efetivada a análise dos editais e dos critérios de avaliação de outros programas similares, buscando visualizar os pontos fortes e fracos do Uma ideia na cabeça uma inovação na mão. A partir daí, foram elaboradas sugestões baseadas nessa comparação, de modo que o trabalho venha a contribuir para o fortalecimento desse programa no IFBA.

$\mathrm{Na}$ análise foram demonstrados o percurso do programa de ideias do IFBA e a confirmação da aderência dele à política interna de inovação. Conclui-se, então, que o propósito do concurso está em consonância com a política de inovação do Instituto. O objetivo maior da gestão de inovação do Instituto é, a partir da Lei n. 10.973/2004, fomentar a inovação e o empreendedorismo com foco no crescimento regional e nacional.

Quando visualizados os pontos fortes e fracos do programa do IFBA, a partir da análise comparativa dos editais com outros órgãos, foram elencadas algumas propostas de melhorias. Reforçar os investimentos nas premiações, como forma de motivação para se obter majoração no número de propostas submetidas, foi uma das propostas. Outra sugestão foi a abertura de inscrição para inventores independentes e externos ao Instituto, aumentando, assim, a visibilidade do concurso.

Como já mencionado, a partir da comparação com os outros editais de programas similares, este trabalho buscou fazer a análise e a avaliação da ação indutora de inovação do IFBA, focando na eficácia desse tipo de ação. É importante ressaltar que não há intenção de criar um novo modelo no formato desses programas, já que, a partir desse artigo, pretende-se contribuir com sugestões de melhorias para que o programa do Instituto, a cada dia, melhore sua forma de inovar.

Ademais, conclui-se que o concurso do IFBA é relevante no cenário de inovação e empreendedorismo na Bahia, pois se mostra eficaz quanto à indução de ideias. Acredita-se que, em uma nova edição do concurso, as sugestões aqui propostas contribuirão para ampliar a visibilidade desse concurso.

Por fim, não foi escopo desta pesquisa a verificação da efetivação no mercado das ideias induzidas no programa do IFBA. Por isso, não se avaliou se alguma ideia induzida gerou produto ou serviço para a instituição ou para a sociedade. Sugere-se, portanto, como trabalho futuro, fazer esse tipo de análise. 


\section{Referências}

ALMEIDA, M. M. J.; TEIXEIRA, F. L. C. Políticas públicas de Ct\&I na Bahia: um estudo das ações da secti no período de 2005 a 2014. In: ALTCC, 2015, Porto Alegre, RS (on-line). Anais [...]. Porto Alegre: ALTEC, 2015. Disponível: http://altec2015.nitec.co/altec/papers/1040.pdf . Acesso em: 7 maio 2020.

ANP - AGÊNCIA NACIONAL DO PETRÓLEO. Prêmio ANP de Inovação Tecnológica 2018. Disponível em: http://www.anp.gov.br/pesquisa-desenvolvimento-inovacao/302-premio-anp-deinovacao-tecnologica/edicoes-anteriores/4443-premio-anp-de-inovacao-tecnologica-2018. Acesso em: 9 abr. 2019.

ARBIX, G.; CONSONI, F. Inovar para transformar a Universidade brasileira. RBCS, [s.l.], v. 26, n. 77, outubro, 2011. Disponível em: http://www.scielo.br/pdf/rbcsoc/v26n77/16.pdf. Acesso em: 22 set. 2018.

BAGGIO, A. F.; BAGGIO, D. K. Empreendedorismo: Conceitos e Definições. Revista de Empreendedorismo, Inovação e Tecnologia, [s.l.], v. 1, n. 1, p. 25-38, 2014. ISSN 2359-3539. Disponível em: https://seer.imed.edu.br/index.php/revistasi/article/view/612. Acesso em: 20 dez. 2019.

BARON, R. A.; SHANE, S. Empreendedorismo: uma visão do processo. São Paulo: Thomson Learning, 2007.

BRASIL. Ministério da Ciência, Tecnologia, Inovações e Comunicações. Estratégia Nacional de Ciência, Tecnologia e Inovação (2016-2022). Brasília, DF: MCTI. 2016.

BRASIL. Lei n. 10.973, de 2 dezembro de 2004. Lei de Inovação Tecnológica. Brasília, DF: Senado Federal, 2004.

BRASIL. Lei n. 13.243, de 11 janeiro de 2016. Novo Marco Legal. Brasília, DF: Senado Federal, 2016.

DAVIDSON, P. Researching entrepreneurship. New York: Springer, 2005.

DORNELAS, J. C. A. Empreendedorismo: transformando ideias em negócios. Rio de Janeiro:

Elsevier; Campus, 2008. Disponível em: https://books.google.com.br/books?hl=pt-BR\&lr=\&id=oKla yz7rBVIC\&oi $=$ fnd\&pg $=$ PA1\&dq $=$ DORNELAS,+ J. + C. + A. + Empreendedorismo\&ots $=$ PJAKLe 1 av $\mathrm{H} \& \mathrm{sig}=24 \mathrm{BHzY} 439 \mathrm{mbKGqUkLTMOSo6zWsg \# v}=$ onepage\&q=DORNELAS\% 2C\%20J.\%20C.\%20 A.\%20Empreendedorismo\&f=false. Acesso em: 12 jan. 2018.

ENAP - ESCOLA NACIONAL DE ADMINISTRAÇÃO PÚBLICA. Concurso Inovação. [2018]. Disponível em: https://inovacao.enap.gov.br/. Acesso em: 15 dez. 2018.

ETZKOWITZ, H.; ZHOU, C. Hélice Tríplice: inovação e empreendedorismo universidade- indústriagoverno. Estud. Av., São Paulo, v. 31, n. 90, p. 23-48, maio 2017. Disponível em: http://www.scielo. $\mathrm{br} / \mathrm{scielo} . \mathrm{php}$ ?script $=$ sci_arttext\&pid=S0103-40142017000200023\&lng $=$ en\&nrm $=$ iso. Acesso em: 18 fev. 2019.

FAPESB - FUNDAÇÃO DE AMPARO À PESQUISA NA BAHIA. Apoio à Inovação. [2020]. Disponível em: http://www.fapesb.ba.gov.br/apoio-a-inovacao/. Acesso em: 5 fev. 2020.

IBGE - INSTITUTO BRASILEIRO DE GEOGRAFIA E ESTATÍSTICA. Pesquisa de Inovação 2017. Disponível em: https://biblioteca.ibge.gov.br/visualizacao/livros/liv101706_notas_tecnicas.pdf .

Acesso em: 4 maio 2020. 
IFBA - INSTITUTO FEDERAL DA BAHIA. Aberta as inscrições para a $6^{\circ}$ edição do "Uma ideia na cabeça, uma inovação na mão". [2019]. Disponível em: http://www.prpgi.ifba.edu.br/abertaas- inscricoes-para-a-6a-edicao-do-uma-ideia-na-cabeca-uma-inovacao-na-mao/. Acesso em: 5 fev. 2019.

IFBA - INSTITUTO FEDERAL DA BAHIA. Política de Inovação IFBA. [2020]. Disponível em: https://portal.ifba.edu.br/prpgi/noticias/2019/pdf/politica-inovacao-ifba.pdf . Acesso em: 4 maio 2020.

IGI - INDÍCE GLOBAL DE INOVAÇÃO. Global Innovation Index 2019 rankings. [2020].

Disponível em: https://www.globalinnovationindex.org/gii-2019-report. Acesso em: 4 maio 2020.

INVENT FOR THE PLANET. Invent for the Planet 2019 - The sun never sets on innovation. [2019]. Disponível em: http://dippg.cefet-rj.br/index.php/pt/component/content/article/59evento/291-iftp?Itemid=0. Acesso em: 11 abr. 2019.

IPEA - INSTITUTO DE PESQUISA ECONÔMICA APLICADA. Avaliação das Políticas de Incentivo à P\&D e Inovação Tecnológica no Brasil. Brasília: Ipea, 2018.

MIRANDA, J. I. R.; LIMA VERDE, L. H. O futuro da propriedade intelectual do Brasil. [2019]. Disponível em: https://repositorio.ifgoiano.edu.br/bitstream/prefix/269/1/Lima\%20Verde\%20\%26\%20 Miranda\%202019\%20-\%200\%20futuro\%20da\%20propriedade\%20intelectual\%20no\%20Brasil. pdf. Acesso em: 30 abr. 2020.

REIS, D. R. Gestão da Inovação tecnológica. 1. ed. São Paulo: Manole, 2011.

SCHUMPETER, J. A. Capitalismo, Socialismo e Democracia. São Paulo: Editora Unesp Digital, 2017.

SCOTT, A. Inovação do Planejamento à ação. São Paulo: M. Books, 2016.

SEBRAE - SERVIÇO BRASILEIRO DE APOIO ÀS MICROS E PEQUENAS EMPRESAS. Edital Sebrae de Inovação. [2017]. Disponível em: http:/www.sebrae.com.br/sites/PortalSebrae/artigos/ edital- sebrae-de-inovacao-inscreva-seu-projeto,fa7b8e61bc125510VgnVCM1000004c00210aRC RD. Acesso em: 2 dez. 2018.

SECTI - SECRETARIA DE CIÊNCIA, TECNOLOGIA E INOVAÇÃO. Programa Estadual de Incentivo à Inovação Tecnológica - INOVATEC. [2020]. Disponível em: http://www.secti.ba.gov. br/modules/conteudo/conteudo.php?conteudo=13. Acesso em: 15 mar. 2020.

SEEDS FOR THE FUTURE. Seeds for the future 2016. Disponível em: https://www.huawei.com/ minisite/br/seedsforthefuture2016/index.html\#programa. Acesso em: 5 maio 2020.

UFBA - UNIVERSIDADE FEDERAL DA BAHIA. Propci divulga edital Paldeia de inovação tecnológica. 2015. Disponível em: https://www.ufba.br/ufba_em_pauta/propci-divulga-editalPaIdeia-de-inova\%C3\%A7\%C3\%A3o-tecnol\%C3\%B3gica. Acesso em: 7 dez. 2018.

USP - UNIVERSIDADE DE SÃO PAULO. Inovação na USP: alunos criam soluções usando a internet das coisas. [2016]. Disponível em: https://jornal.usp.br/universidade/inovacao-na-uspalunos- criam-solucoes-usando-a-internet-das-coisas/. Acesso em: 12 dez. 2018.

VILLAGE TO RAISE A CHILD. The village to raise a child 2018 application is closed.

Disponível em: http://ignitinginnovationsummit.com/program. Acesso em: 3 abr. 2019. 
WEWORK. WeWork Creator Awards 2019. Disponível em: https://creatorawards.wework.com/ptBR/. Acesso em: 10 abr. 2019.

\section{WIPO - WORLD INTELLECTUAL PROPERTY ORGANIZATION. Índice Global de Inovação} 2018. Disponível em: https://www.wipo.int/edocs/pubdocs/pt/wipo_pub_gii_2018-abridged1.pdf. Acesso em: 7 mar. 2019.

WIPO - WORLD INTELLECTUAL PROPERTY ORGANIZATION. Índice Global de Inovação 2019. Disponível em: https://www.wipo.int/export/sites/www/pressroom/pt/documents/pr_2019_834. pdf. Acesso em: 2 maio 2020.

YIN, R. K. Estudo de caso: planejamento e métodos. 2 ed. Porto Alegre: Bookman, 2001.

\section{Sobre os Autores}

\section{Jamile Rosendo de Oliveira}

E-mail: jamile.rosendo@gmail.com

Mestre em Propriedade Intelectual e Transferência de Tecnologia para Inovação pelo PROFNIT-IFBA em 2019.

Endereço profissional: IFBA, Reitoria, Avenida Araújo Pinho, n. 39, Canela. CEP: 40110-150.

\section{Wagna Piler Carvalho dos Santos}

\section{E-mail:wagna.ifba@gmail.com}

Doutorado em Química pela Universidade Federal da Bahia em 2007.

Endereço profissional: IFBA, Campus Salvador, Rua Emídio dos Santos, s/n Barbalho, Salvador, BA. CEP: 40301-015.

\section{Núbia Moura Ribeiro}

E-mail: nubiamouraribeiro@gmail.com

Doutorado em Química pela Universidade Federal do Rio de Janeiro em 2004.

Endereço profissional: Instituto Federal da Bahia, Campus de Jequié, Departamento de Ensino, Loteamento

Cidade Nova, John Kennedy, Jequié, BA. CEP: 45201-570.

\section{Eduardo Manuel de Freitas Jorge}

E-mail: emjorge1974@gmail.com

Doutorado em Difusão do Conhecimento pela Universidade Federal da Bahia em 2012

Endereço profissional: Universidade do Estado da Bahia, rua Silveira Martins, n. 2.555, Cabula, Salvador, BA.

CEP: 41150-000.

\section{Marcio Luis Valenca Araujo}

E-mail: maraujo.va lenca@gmail.com

Doutor em Modelagem Computacional pelo SENAI/CIMATE em 2018.

Endereço profissional: IFBA, Campus Santo Amaro, Tv. Santo Amaro, n. 44 Santo Amaro, BA. CEP: 44200-000. 